\title{
Commentary: Right middle lobe can be a friend or a foe after lobectomy
}

\author{
Benjamin R. Zambetti, MD, and \\ Thomas Ng, MD, FRCSC, FACS
}

In this issue of the Journal, Yamagishi and colleagues ${ }^{1}$ have used computed tomography (CT) volumetric and structural analysis to assess which lung fields contribute most to pulmonary function compensation after right lower lobectomy. The authors retrospectively reviewed 53 patients undergoing right lower lobectomy for living-donor lung transplantation. CT scan and pulmonary function data were obtained preoperatively and postoperatively at 3 and 12 months, with the authors finding lung expansion and functional compensation to be heterogenous, greatest seen within the right middle lobe. As the pulmonary function tests at 12 months were significantly greater than that predicted preoperatively by either segmental counting or CT volumetrics, the authors concluded that this pulmonary function compensation was mainly due to the contribution of the right middle lobe.

While the data presented by Yamagishi and colleagues ${ }^{1}$ show a unique and interesting physiologic response to right lower lobectomy, these results must not be misinterpreted and should not be used to justify proceeding with lobectomy in patients with poor pulmonary function.

The cohort studied by Yamagishi and colleagues ${ }^{1}$ were young, healthy, and without pulmonary disease, which is far different from the typical patient undergoing right lower lobectomy for lung cancer. It cannot be assumed that the right middle lobe compensation found by the authors also applies to abnormal lungs, specifically those with emphysema-the common patients for whom thoracic surgeons

\footnotetext{
From the Division of Thoracic Surgery, University of Tennessee Health Science Center College of Medicine, Memphis, Tenn.

Disclosures: The authors reported no conflicts of interest.

The Journal policy requires editors and reviewers to disclose conflicts of interest and to decline handling or reviewing manuscripts for which they may have a conflict of interest. The editors and reviewers of this article have no conflicts of interest.

Received for publication Aug 29, 2020; revisions received Aug 29, 2020; accepted for publication Aug 31, 2020; available ahead of print Sept 3, 2020.

Address for reprints: Thomas Ng, MD, FRCSC, FACS, 1325 Eastmoreland Ave, Suite 460, Memphis, TN 38104 (E-mail: tng4@uthsc.edu).

J Thorac Cardiovasc Surg 2021;162:1424-5

$0022-5223 / \$ 36.00$

Copyright (c) 2020 by The American Association for Thoracic Surgery

https://doi.org/10.1016/j.jtcvs.2020.08.104
}



CENTRAL MESSAGE

The middle lobe allows

compensation of pulmonary

function after right lower lobec-

tomy but this does not apply to

all lobectomies as the middle

lobe bronchus tends to kink after

right upper lobectomy.

care, so further study is required for this population. Furthermore, the time points evaluated were at 3 and 12 months; therefore, is it not known if pulmonary compensation (if any at all) occurs immediately after surgery, the period that is vital with regards to postoperative complications.

Finally, one must be reminded that the study only evaluated patients undergoing right lower lobectomy; thus, we should not mistakenly conclude that the results also apply to all right-sided lobectomies. As thoracic surgeons, we have all experienced a troublesome right middle lobe after right upper lobectomy, where it develops atelectasis (Figure 1,A) due to kinking of the middle lobe bronchus (Figure 1, B) from postresection shifting, leading to worse pulmonary function than would be anticipated. In a series reported by Masuda and colleagues, ${ }^{2}$ this problem with the right middle lobe occurred with an incidence of $11 \%$ after right upper lobectomy, and there seems to be no effective measure to prevent this complication. Therefore, although Yamagishi and colleagues ${ }^{1}$ found the middle lobe to be a "friend" after right lower lobectomy, the middle lobe can also be a "foe" after right upper lobectomy. 

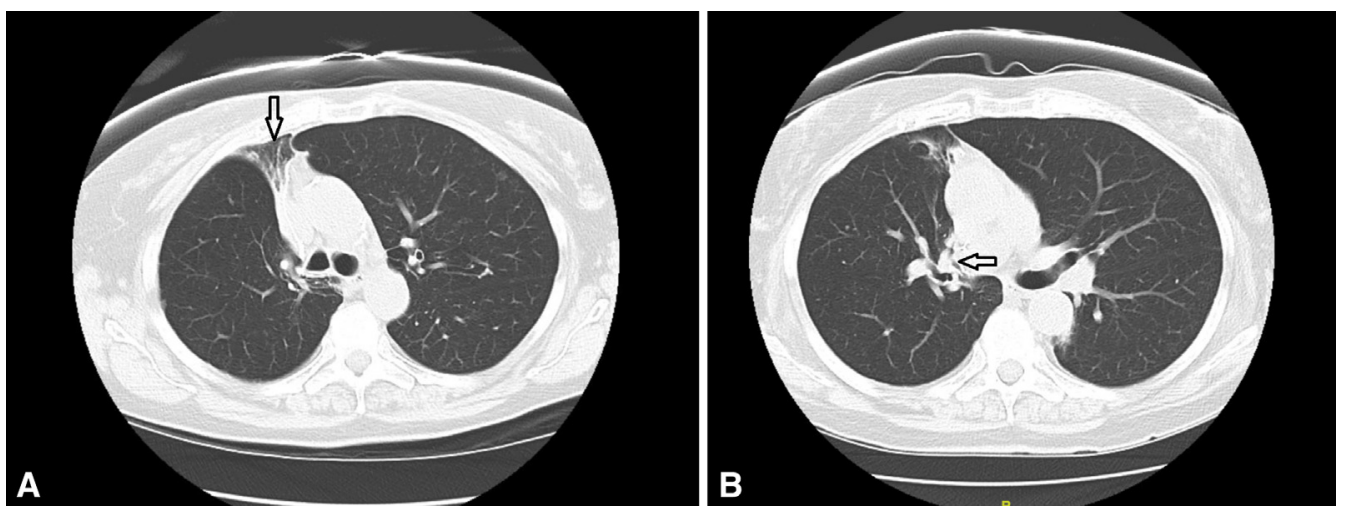

FIGURE 1. Computed tomography scan after right upper lobectomy showing (A) right middle lobe atelectasis (arrow), due to (B) kinked right middle lobe bronchus (arrow).

\section{References}

1. Yamagishi H, Chen-Yoshikawa TF, Oguma T, Hirai T, Date H. Morphological and functional reserves of the right middle lobe: radiological analysis of changes after right lower lobectomy in healthy individuals. J Thorac Cardiovasc Surg. 2021; 162:1417-23.e2.
2. Masuda Y, Marutsuka T, Suzuki M. A risk factor for kinked middle lobar bronchus following right upper lobectomy. Asian Cardiovasc Thorac Ann. 2014; 22:955-9.
See Article page 1417.

\section{Commentary: Is less really more?}

\author{
Dirk Van Raemdonck, MD, PhD
}

"Whatever you save is also earned" is one of the famous inspirational KalimaQuotes. ${ }^{1}$ During lung resection, functional parenchyma should be spared as much as possible to not compromise postoperative breathing and quality of life for the patient's remaining time.

Compared with liver parenchyma, ${ }^{2}$ the mechanism leading to compensatory lung growth after pulmonary resection is less clear. ${ }^{3}$ Serial changes in pulmonary function after

From the Department of Thoracic Surgery, University Hospitals Leuven, Leuven, Belgium; and Department of Chronic Diseases and Metabolism, Katholieke Universiteit Leuven, Leuven, Belgium.

Disclosures: The author reported no conflicts of interest.

The Journal policy requires editors and reviewers to disclose conflicts of interest and to decline handling or reviewing manuscripts for which they may have a conflict of interest. The editors and reviewers of this article have no conflicts of interest.

Received for publication Aug 17, 2020; revisions received Aug 17, 2020; accepted for publication Aug 17, 2020; available ahead of print Aug 20, 2020.

Address for reprints: Dirk Van Raemdonck, MD, PhD, Department of Thoracic Surgery, University Hospital Gasthuisberg, Herestraat 49, B-3000 Leuven, Belgium (E-mail: dirk.vanraemdonck@uzleuven.be).

J Thorac Cardiovasc Surg 2021;162:1425-7

0022-5223/ $\$ 36.00$

Copyright (c) 2020 by The American Association for Thoracic Surgery

https://doi.org/10.1016/j.jtcvs.2020.08.051

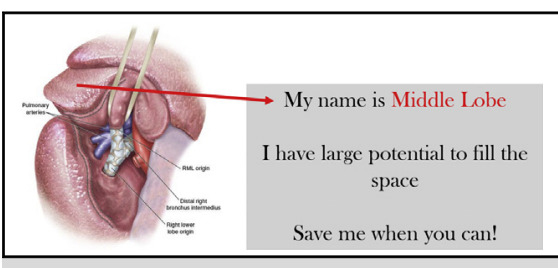

Whatever you save is also earned.

CENTRAL MESSAGE

Two segments of the middle lobe have larger potential than 3 segments of the upper lobe to increase pulmonary volume and function in the first year after right lower lobectomy in healthy individuals.

anatomic lung resection have been well studied. Actual pulmonary function, particularly forced expiratory volume in 1 second and diffusion capacity for carbon monoxide, 